\title{
Molecular and Biochemical Basis of Intermediate Maple Syrup Urine Disease Occurrence of Homozygous G245R and F364C Mutations at the E1 $\alpha$ Locus of Hispanic-Mexican Patients
}

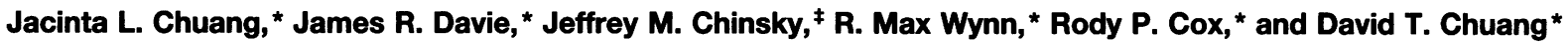 \\ *Departments of Biochemistry and Internal Medicine, University of Texas Southwestern Medical Center, Dallas, Texas 75235; and \\ ${ }^{\ddagger}$ Division of Human Genetics, Department of Pediatrics, University of Maryland School of Medicine, Baltimore, Maryland 21201
}

\begin{abstract}
Maple syrup urine disease (MSUD) is caused by a deficiency of the mitochondrial branched-chain $\alpha$-keto acid dehydrogenase (BCKAD) complex. The multienzyme complex comprises five enzyme components, including the $\mathrm{E} 1$ decarboxylase with a heterotetrameric $\left(\alpha_{2} \beta_{2}\right)$ structure. Four unrelated Hispanic-Mexican MSUD patients with the intermediate clinical phenotype were diagnosed 7 to 22 mo after birth during evaluation for developmental delay. Three of the four patients were found homozygous for $G$ to $A$ transition at base 895 (exon 7) of the E1a locus, which changes Gly-245 to Arg (G245R) in that subunit. The remaining patient was homozygous for $T$ to $G$ transversion at base 1,253 in the E1a gene, which converts Phe-364 to Cys (F364C) in the gene product. Transfection studies in E1 $\alpha$ deficient lymphoblasts indicate that both G245R and F364C mutant E1 $\alpha$ subunits were unable to significantly reconstitute BCKAD activity. Western blotting showed that both mutant E1 $\alpha$ subunits in transfected cells failed to efficiently rescue the normal E1 $\beta$ through assembly. The putative assembly defect was confirmed by pulse-chase labeling of E1 subunits in a chaperone-augmented bacterial overexpression system. The kinetics of initial assembly of the G245R E1 $\alpha$ subunit with the normal E1 $\beta$ was shown to be slower than the normal E1 $\alpha$. No detectable assembly of the F364C E1 $\alpha$ subunit with normal E1 $\beta$ was observed during the $2 \mathrm{~h}$ chase. Small amounts of recombinant mutant E1 proteins were produced after $15 \mathrm{~h}$ induction with isopropyl thiogalactoside and exhibited very low or no E1 activity. Our study establishes that G245R and F364C mutations in the E1 $\alpha$ subunit disrupt both the E1 heterotetrameric assembly and function of the BCKAD complex. Moreover, the results suggest that the G245R mutant E1 $\alpha$ allele may be important in the Hispanic-Mexican population. ( $J$. Clin. Invest. 1995. 95:954-963.) Key words: branched-chain $\alpha$ keto acid dehydrogenase complex $\bullet$ E1 dysfunction • pulsechase labeling - defective heterotetrameric assembly $\bullet$ molecular chaperones
\end{abstract}

Address correspondence to David T. Chuang, Ph.D., Department of Biochemistry, University of Texas Southwestern Medical Center, 5323 Harry Hines Blvd., Dallas, TX 75235-9038. Phone: 214-648-2457; FAX: 214-648-8856; e-mail: COX02@UTSW.SWMED.EDU.

Received for publication 18 July 1994 and in revised form 18 November 1994.

J. Clin. Invest.

(C) The American Society for Clinical Investigation, Inc.

0021-9738/95/02/0954/10 \$2.00

Volume 95, March 1995, 954-963

\section{Introduction}

Maple syrup urine disease (MSUD) ${ }^{1}$ or branched-chain $\alpha$-ketonuria is an autosomal recessively inherited deficiency in the mitochondrial branched-chain $\alpha$-keto acid dehydrogenase (BCKAD) complex. The biochemical basis of this disease is the inability to metabolize branched-chain $\alpha$-keto acids (BCKAs) derived from the essential branched-chained amino acids (BCAAs) leucine, isoleucine, and valine. The elevated BCAAs and BCKAs may have severe clinical consequences including ketoacidosis, mental retardation, and neurological impairment. Variations in clinical presentations have led to the classification of MSUD into five clinical phenotypes, i.e., classic, intermediate, intermittent, thiamine-responsive, and E3-deficient $(1,2)$. The classic form, which comprises $75 \%$ of MSUD patients, is manifested within the first 2 wk of life with poor feeding, lethargy, seizures, coma, and death if untreated. Intermediate MSUD is associated with elevated BCAAs and BCKAs, with progressive mental retardation and developmental delay without a history of catastrophic illness. The diagnosis is usually delayed for many months. An intermittent form of MSUD may have normal levels of BCAAs, normal intelligence and development until a stress, e.g., infection, precipitates decompensation with ketoacidosis and neurologic symptoms, which are usually reversed with dietary treatment. Thiamine-responsive MSUD is similar to the intermediate phenotype but responds to pharmacologic doses of thiamine with normalization of BCAAs. The E3deficient MSUD is caused by defects in the dehydrogenase (E3) component of the $\mathrm{BCKAD}$ complex that is common to the pyruvate and $\alpha$-ketoglutarate dehydrogenase complexes. $\mathrm{Pa}$ tients with E3 deficiency have dysfunction of all three enzyme complexes, and patients usually die in infancy with severe lactic acidosis (3).

The mammalian BCKAD complex is a mitochondrial multienzyme complex, which catalyzes the oxidative decarboxylation of the three BCKAs derived from BCAAs $(4,5)$. The enzyme complex is organized around a cubic core comprising 24 identical dihydrolipoyl transacylase (E2) subunits. The other enzyme components attached to the E2 core include a branched-chain $\alpha$-keto acid decarboxylase (E1), a dihydrolipoamide dehydrogenase (E3), a specific kinase and a specific phosphatase. The latter two enzyme components are responsible for the regulation of BCKAD complex by phosphorylation (inactivation)/de-

1. Abbreviations used in this paper: $\mathrm{BCAA}$, branched-chain amino acid; BCKA, branched-chain $\alpha$-keto acid; BCKAD, branched-chain $\alpha$-keto acid dehydrogenase; E1, branched-chain $\alpha$-keto acid decarboxylase; E2, dihydrolipoyl transacylase; E3, dihydrolipoyl dehydrogenase; Hsp, heatshock protein; IPTG, isopropyl thiogalactoside; MSUD, maple syrup urine disease; SSCP, single-stranded conformational polymorphism; TEV, tobacco etch virus; TPP, thiamine pyrophosphate. 


\begin{tabular}{lclccc}
\hline Patient & Age at diagnosis & \multicolumn{1}{c}{ Presenting symptoms } & $\begin{array}{c}\text { Plasma leucine } \\
\mu M\end{array}$ & $\begin{array}{c}\text { Dietary leucine* tolerance } \\
m g / k g \text { per day }\end{array}$ & $\begin{array}{c}\text { Developmental status (assessed } \\
\text { age/chronological age) }\end{array}$ \\
\hline A. G. & $12 \mathrm{mo}$ & Developmental delay, seizure disorder & 2572 & $40-50$ & $6.0 \mathrm{yr} / 8.0 \mathrm{yr}$ \\
J. B. & $16 \mathrm{mo}$ & Developmental delay, seizure disorder & 1225 & $10-50$ & $8.0-9.0 \mathrm{yr} / 15 \mathrm{yr}$ \\
P. R. & $7 \mathrm{mo}$ & Developmental delay & $1218^{\ddagger}$ & 50 & $20 \mathrm{mo} / 27 \mathrm{mo}$ \\
B. S. & $22 \mathrm{mo}$ & Developmental delay, seizure disorder & 3347 & 70 & $12-18 \mathrm{mo} / 5 \mathrm{yr}$ \\
\hline
\end{tabular}

* Total dietary leucine tolerated to maintain plasma leucine concentrations of $200-400 \mu \mathrm{M}$ (normal range $50-130 \mu \mathrm{M}$ ). ${ }^{\ddagger}$ Level obtained on partially restricted protein intake ( $1 \mathrm{~g} / \mathrm{kg} /$ day). A. G., J. B., P. R., and B. S. are intermediate MSUD patients.

phosphorylation (activation) (6). The E1 component is a heterotetramer consisting of two $\mathrm{E} 1 \alpha\left(47,000 M_{\mathrm{r}}\right)$ and two $\mathrm{E} 1 \beta$ $\left(37,000 M_{\mathrm{r}}\right)$ subunits. The E3 component, a flavoprotein, is a homodimer. Both kinase and phosphatase are products of single genes. Multiple copies of the six distinct subunits of the BCKAD complex are synthesized in the cytosol and imported into the mitochondria (7). In the matrix space of this organelle, mature subunits are assembled into a multienzyme complex of 4-5 $\times 10^{6}$ daltons.

MSUD is genetically heterogeneous, and mutations in E1 $\alpha$, $\mathrm{E} 1 \beta, \mathrm{E} 2$ and $\mathrm{E} 3$ loci have been identified (1). Some of these mutations have been characterized at the molecular and biochemical level. For example, the Y393N substitution in E1 $\alpha$, which is present in Mennonite patients with classic MSUD, was shown to impede E1 assembly resulting in the preferential degradation of $\operatorname{E} 1 \beta(8,9)$. However, these studies were confined to classic MSUD patients, and little is known about the variant forms of MSUD. In the present report, we describe the clinical and molecular characterization of four MSUD patients with an intermediate phenotype. These patients, all of HispanicMexican origin, were identified many months after birth during evaluation for developmental delay, without acute neurologic symptoms. Molecular studies show that three of the four unrelated patients are homozygous for a missense mutation in the $\mathrm{E} 1 \alpha$ locus. The remaining patient is homozygous for a second mutation also in the $\mathrm{E} 1 \alpha$ gene. Both mutations produce inactive or slightly active $\mathrm{BCKAD}$ complex when the mutant peptide was transiently expressed in E1 $\alpha$-deficient lymphoblasts. Moreover, by pulse-chase labeling of E1 subunits synthesized in Escherichia coli, we show that these mutations in E1 $\alpha$ alter the kinetics of assembly with $\mathrm{E} 1 \beta$.

\section{Methods}

Case reports. A.G., a male Mexican infant, appeared normal during the first few months of life except for mild feeding problems. Although development seemed normal during the first 5-6 mo of age, he was unable to sit without support until 11 mo of age. During infancy, he sustained several 30-s tonic seizures associated with fever. He presented at $12 \mathrm{mo}$ of age for evaluation of his developmental delay and possible seizure disorder. Physical exam was significant for relative microcephaly (10th percentile compared with length and weight, 75th and 25th percentiles, respectively), mild hypotonia with cerebellar ataxia. MSUD was diagnosed on the basis of elevated serum BCAAs and alloisoleucine (Table I). After initiation of BCAA-restricted diet, neurologic evaluation showed normal tone, reflexes, and cerebellar function.

J.B. was a 5-lb male born to Mexican parents of small stature $(<10$ th percentile $)$. During infancy, he had formula intolerance and exhibited significant developmental delay, manifested by inability to sit, stand, or crawl by 17 mo old. He had two brief tonic/clonic seizures at $4 \mathrm{mo}$, which were easily controlled with phenobarbital. At $17 \mathrm{mo}$, examination was significant for developmental delay; head circumference, length, and weight at the third percentile; and generalized hypotonia. Analysis of serum amino acids demonstrated elevated BCAAs and alloisoleucine, suggesting MSUD. Improved development occurred during dietary treatment, but hyperkinesis and psychomotor delay persisted.

P.R., a Mexican female, demonstrated excessive irritability, poorly tolerated her formula, and showed developmental delay with poor head control, inability to roll over and poor social interactions during the first 4-5 mo of life. Qualitative analysis of serum amino acids showed elevated amino acids including BCAAs. She was placed on $1 \mathrm{~g}$ protein/ kg per day diet with improvement in her reactions to auditory and visual stimuli, decreased ataxia and a weight gain. At 7 mo, physical examination revealed length 75 th, weight 50th, and head circumference 75th percentiles with generalized hypotonia and developmental delay. Quantitative serum amino acids revealed elevated BCAAs and alloisoleucine. Strict dietary treatment resulted in further improvement in her development (Table I).

B.S. was a $6 \mathrm{lb} 8 \mathrm{oz}$ female born to a $14 \mathrm{yr}$-old-Mexican primigravida. Although irritable as an infant she had a good appetite and tolerated standard formula. During her first year of life she was hospitalized four times with pneumonia. At 9 mo, developmental delay was noted and an EEG was normal. Between 12 and $22 \mathrm{mo}$, three uncomplicated tonic/clonic seizures occurred and were controlled with phenobarbital. At $20 \mathrm{mo}$, she was readmitted to the hospital with an infection and evaluated for her developmental abnormalities, being unable to stand or control head movements. Physical examination showed length 30 th, weight 60 th, and head circumference 50th percentiles with diffuse hypotonia, brisk reflexes, and poor motor control. Psychomotor functioning was at a 3-4-mo level. An EEG showed a disorganized pattern with paroxysmal spikes, and a CT scan revealed increased white matter lucency consistent with deficient myelinization. A diagnosis of MSUD was made by metabolic studies (elevated serum BCAAs and alloisoleucine), however, compliance with therapy was poor, and her most advanced milestones are independent walking with a broad-based gait, and a few words $(\leq 10)$ were learned. During periods of appropriate BCAA restriction, her motor and developmental skills demonstrated marked improvement.

Cell cultures and other cell lines. Fibroblast cultures were derived from skin biopsies and grown in monolayer culture as previously described (10). Intermediate MSUD patients A.G., J.B., P.R., and B.S. and classic MSUD patient P.V. were provided by Drs. Arthur Beaudet and Edward McCabe (Baylor College of Medicine, Houston, TX). GM649 was purchased from the Human Genetic Mutant Cell Repository (Camden, NJ). B.F. was a classic MSUD patient of African-American descent provided by Dr. David Valle (John F. Kennedy Institute, Baltimore). K.U. is a classic Caucasian MSUD patient provided by Dr. Selma Snyderman (New York University Medical Center, New York). L.C. is a classic MSUD patient obtained from the Cell Repository at McGill Medical Center (Montreal, Canada). H.H. is a classic Mennonite MSUD patient provided by Dr. Marc Yudkoff (Childrens Hospital of 
Philadelphia, PA). S.B. is a classic MSUD patient provided by Dr. Lisa Dahl (University of Minnesota Medical Center, Minneapolis, MN). Classic MSUD fetal fibroblasts, A-1, were obtained from Dr. Rivka Carmi (Saroka Medical Center, Beer Sheva, Israel). Lymphoblasts were grown in RPMI-1640 medium containing 15\% heat-inactivated fetal calf serum as described previously (8).

Single-stranded conformational polymorphism (SSCP) analysis. All 9 exons of the human E1 $\alpha$ gene were amplified by PCR using primers for the flanking intronic sequences (12). The PCR reaction was carried out in Tris- $\mathrm{HCl} \mathrm{pH} 9.0(10 \mathrm{mM}), \mathrm{MgCl}_{2}(1 \mathrm{mM}), \mathrm{KCl}(50 \mathrm{mM})$, $0.1 \%$ Triton X-100, dNTPs $(0.2 \mu \mathrm{M}$ each $)$, Taq DNA polymerase $(2.5$ $\mathrm{U})$ and $1 \mu \mathrm{M}$ of each sense and antisense primer. To the reaction mixture, $10 \mu \mathrm{Ci}$ of ${ }^{32} \mathrm{P}$-dCTP and $200 \mathrm{ng}$ of genomic DNA as template was added, and the reaction cycled 35 times at $94^{\circ} \mathrm{C}$ for $30 \mathrm{~s}, 55^{\circ} \mathrm{C}$ for $30 \mathrm{~s}$, and $72^{\circ} \mathrm{C}$ for $1 \mathrm{~min} .3 \mu \mathrm{l}$ of ${ }^{32} \mathrm{P}$-labeled PCR product were diluted with $27 \mu \mathrm{l}$ of a solution containing $95 \%$ formamide, $20 \mathrm{mM}$ EDTA, $0.05 \%$ bromophenol blue, $0.05 \%$ xylene cyanol $\mathrm{FF}$ and $37 \mathrm{mM}$ methyl mercury hydroxide. Samples were then heated at $100^{\circ} \mathrm{C}$ for $2 \mathrm{~min}$ and chilled on ice. Electrophoresis with $3 \mu \mathrm{l}$ per lane of each sample applied was carried out on a $0.5 \times \mathrm{MDE}^{\mathrm{TM}}$ gel (J. T. Baker Inc., Phillipsburg, $\mathrm{NJ})$ at constant 6 watts for 18-20 h in $1 \times$ TBE buffer. The gels were dried on filter paper and exposed to Kodak X-OMAT film.

Expression and site-directed mutagenesis of El $\alpha$ cDNA. The construction of the EBO vector for normal human E1 $\alpha$ and methods for transient expression and selection of transfected cells have been previously described (8). The EBO-pLpp parental plasmid (11) contains OriP as the origin of replication. The plasmid also harbors the EBNA1 sequence encoding Epstein-Barr virus nuclear antigen and the hygromycin phosphotransferase sequence that confers antibiotic resistance. The presence of OriP and EBNA-1 sequences allows efficient episomal replication of the plasmid in Epstein-Barr virus transformed lymphoblastoid cells. Nucleotide changes were carried out using the Altered Site ${ }^{\mathrm{TM}}$ in vitro mutagenesis system from Promega (Madison, WI). The chimeric bh E1 $\alpha$ cDNA containing the bovine mitochondrial targeting and the mature human sequences $(8)$ was cloned into pAlter-1 vector, which contained a mutation in the ampicillin-resistant gene rendering the transformed cell susceptible to the antibiotic. Single strand DNA was prepared from the pAlter-bh E1 $\alpha$ plasmid. Mutagenic oligonucleotides containing the mutation and the repair oligonucleotide for the ampicillinresistant gene were annealed simultaneously to the single stranded DNA. T4 DNA polymerase and ligase were added to synthesize an ampicillinresistant mutant strand. After two rounds of ampicillin selection, first in the repair minus strain of $E$. coli (BMH71-18 mut S) then in JM109 cells, colonies were picked for plasmid DNA preparation. DNA sequencing was performed to confirm the mutation. DNA fragment containing the mutation were excised from pAlter vector by restriction enzyme digestion and ligated into the EBO expression vector (8).

Construction of pHisT-E1 prokaryotic expression vector. The $5^{\prime}$ portion of the mature human E1 $\alpha$ cDNA sequence was amplified from the pMAL-c2-hE1 $\alpha$ expression vector (9) using an internal 22-mer antisense primer with sequence 5 '-GTAACAGATGTCGACCCTGTT$3^{\prime}$, and a 49-mer sense primer with sequence $5^{\prime}$-GGCTCTAGACTCGAGAATCTTTATTTtcaatcatctctggatgacaagc-3' to yield a $\overline{601-\mathrm{bp}}$ product. The sense primer adds exogenous sequence (shown in upper case) to the 5' terminus of the mature E1 $\alpha$ open-reading frame (shown in lower case). This exogenous sequence includes an Xbal restriction site (shown in bold) followed by sequence encoding the first six amino acids specific for the tobacco etch virus (TEV) protease cleavage (shown underlined). The seventh required amino acid for the TEV protease cleavage is supplied by the amino-terminal serine of the mature E1 $\alpha$ sequence.

To generate the pHisT-E1 $\alpha$ expression vector, the 601-bp amplification product was cut with XbaI and NarI to yield a 454-bp fragment encoding the TEV cleavage site and the 5 ' portion of the E1 $\alpha$ openreading frame. The $\mathrm{pEBO}-\mathrm{hbE} 1 \alpha$ expression vector (8) was cleaved with NarI and XhoI to yield a 1064-bp fragment that encodes the 3' portion of the mature E1 $\alpha$ open-reading frame. Both fragments were ligated into the pTrcHisB expression vector (Invitrogen) digested with
NheI and Xhol to yield the pHisT-E1 $\alpha$ expression vector. To generate the pHisT-E1 expression vector, a BamHI-Scal fragment $(2,555 \mathrm{bp})$ comprising the trc promoter and the mature human $\mathrm{E} 1 \beta$ open-reading frame was isolated from expression vector $\mathrm{pKK}-\mathrm{hE} 1 \beta$ (13) and ligated into the corresponding sites in the host pHisT-E1 $\alpha$ expression vector, yielding the pHisT-E1 expression vector. Mutant E1 $\alpha$ variants of the pHisT-hE1 expression vector were constructed identically, except for the substitution of 1064-bp NarI-XhoI fragments isolated from variant pEBO-hbE1 $\alpha$ plasmids harboring the desired E1 $\alpha$ mutation.

Pulse-chase labeling for kinetics of El $\alpha$ and El $\beta$ assembly. E. coli strain CG-712 and the plasmid pGroESL (for overexpression of chaperonins GroEL and GroES) (14) were received as kind gifts from Dr. Anthony Gatenby of DuPont Experimental Station (Wilmington, DE). CG-712 cells containing the pGroESL plasmid were transformed with pHisT-hE1 expression vectors carrying the normal mature E1 $\beta$ cDNA and either normal or mutant His-tagged mature E1 $\alpha$ cDNA sequences (15). Cells were grown at $42^{\circ} \mathrm{C}$ to an O.D.595 of 0.80 in Cbroth minimal media (16) supplemented with $40 \mu \mathrm{M}$ TPP, $50 \mu \mathrm{g} / \mathrm{ml}$ carbenicillin, and $50 \mu \mathrm{g} / \mathrm{ml}$ chloramphenicol. Cells were pelleted and resuspended in one-fifth original volume of the same media without antibiotics, and allowed to recover with shaking for $5 \mathrm{~min}$ at $37^{\circ} \mathrm{C}$. Cells were subsequently induced with $2 \mathrm{mM}$ isopropyl thiogalactoside (IPTG) for $5 \mathrm{~min}$, pulsed with $50 \mu \mathrm{Ci} / \mathrm{ml}$ of ${ }^{35} \mathrm{~S}$-Cys $/{ }^{35} \mathrm{~S}$-Met (ICN Radiochemicals, Costa Mesa, CA) for $1 \mathrm{~min}$, and chased with three volumes of the same media (without antibiotics) supplemented with $8 \mathrm{mg} / \mathrm{ml}$ each of nonradioactive L-cysteine and L-methionine. At specified time points following the chase, cell samples $(1.8 \mathrm{ml})$ were taken and quickly frozen in liquid $\mathrm{N}_{2}$. Thawed samples were lysed by sonication, and supernatants after microcentrifugation were treated batchwise with an excess $(15 \mu \mathrm{l})$ of $\mathrm{Ni}^{2+}$-NTA (nitrilotriacetic acid) resin from Qiagen (Chatsworth, $\mathrm{CA}$ ). The resin was washed batchwise three times (total volume: 2.4 ml) with $15 \mathrm{mM}$ imidazole in $100 \mathrm{mM}$ potassium phosphate ( $\mathrm{pH} 7.5$ ) containing $2 \mathrm{mM} \mathrm{MgCl}_{2}, 0.1 \mathrm{mM}$ EDTA, $0.1 \mathrm{mM}$ EGTA, $0.2 \mathrm{mM}$ TPP and $2 \mathrm{mM}$ mercaptoethanol. Bound (His) ${ }_{6}$-tagged $\mathrm{E} 1 \alpha$ and assembled untagged $\mathrm{E} 1 \beta$ polypeptides were eluted with $30 \mu \mathrm{l}$ of Laemmli SDSsample buffer (17) containing $50 \mathrm{mM}$ EDTA. Eluted labeled polypeptides were analyzed by SDS-PAGE and fluorography.

Other procedures. The amplification of genomic DNA, the flanking intronic primers, the methods for subcloning and sequencing techniques used in this study were previously described $(12,18)$. Northern and Western blotting were performed as described elsewhere $(8,18,19)$. Assays of decarboxylation rates using $\alpha$-keto $\left[1-{ }^{14} \mathrm{C}\right]$ isovalerate were performed on intact fibroblasts and untransfected and transfected lymphoblasts as previously described (10). The activity of recombinant E1 was assayed radiochemically using $\alpha$-keto $\left[1-{ }^{14} \mathrm{C}\right]$ isovalerate as a substrate and 2,6-dichlorophenolindophenol as an artificial electron acceptor (10).

\section{Results}

Clinical phenotype of intermediate MSUD. As described in Methods, the patients studied in the present report are all of Hispanic-Mexican origin. Their clinical phenotype conforms to that accepted as intermediate MSUD. The patients presented 7-22 mo after birth for evaluation of developmental delay and a mild seizure disorder (Table I). The developmental status of the patients showed significant retardation when their achievement level was compared to their age, (Table I, right column). MSUD was not suspected until a metabolic screen revealed marked elevation of the BCAAs and BCKAs and the presence of alloisoleucine. Plasma leucine in the four patients ranged from $1,218-3,347 \mu \mathrm{M}$ as also shown in Table I. Dietary restriction of BCAAs ameliorates further neurological impairment, and allowed developmental progress to occur (See Methods).

To confirm that the above intermediate MSUD patients are deficient in the decarboxylation of the $\alpha$-keto acids, intact cell 
Table II. Rate of Decarboxylation of $\alpha$-Keto Acids by Intact Normal and MSUD Fibroblasts

\begin{tabular}{lllc}
\hline & \multicolumn{2}{c}{ Decarboxylation rate } & Percent normal \\
\cline { 2 - 3 } \multicolumn{1}{c}{ Cell line } & Pyruvate & KIV & activity with KIV \\
\hline Normal & 0.411 & 0.177 & 100 \\
Classic MSUD & 0.382 & 0 & 0 \\
A. G. & 0.308 & 0.007 & 4.0 \\
J. B. & 0.333 & 0.007 & 4.0 \\
P. R. & 0.489 & 0.010 & 5.6 \\
B. S. & 0.399 & 0 & 0 \\
& & & \\
\hline
\end{tabular}

Intact cells from fibroblast cultures were assayed in triplicate at $2 \mathrm{mM}$ for pyruvate and $\alpha$-ketoisovalerate (KIV). Specific radioactivities were 1,275 and $750 \mathrm{cpm} / \mathrm{nmol}$ for $\left[1-{ }^{14} \mathrm{C}\right]$ pyruvate and $\alpha$-keto $\left[1-{ }^{14} \mathrm{C}\right]-$ isovalerate, respectively. For each assay, $1 \times 10^{6}$ cells $(0.25 \mathrm{mg}$ of protein) were incubated at $37^{\circ} \mathrm{C}$ for $10 \mathrm{~min}$ with labeled pyruvate and 80 min with $\alpha$-ketoisovalerate. A. G., J. B., P. R., and B. S. are intermediate MSUD patients.

assays with cultured fibroblasts were carried out. Table II shows that three of the intermediate patients (A.G., J.B., and P.R.) had 4 to $5.6 \%$ of residual activity compared to normal. These activities are in the range reported for other intermediate MSUD patients $(1,2)$. The fourth patient, B.S., had no detectable activity similar to classic MSUD. The decarboxylation rate with pyruvate was normal in all patients and served as a control for cell viability (Table II). The intact cell results establish that the metabolic block in the intermediate MSUD patients is at the decarboxylation of BCKAs.

Western and Northern blot analysis of normal and mutant cells. Since the BCKAD complex is a heteromultimeric protein, it was necessary to identify which subunit was affected in these individuals with MSUD. Western blotting was carried out using lysates prepared from normal and MSUD fibroblasts. Fig. 1

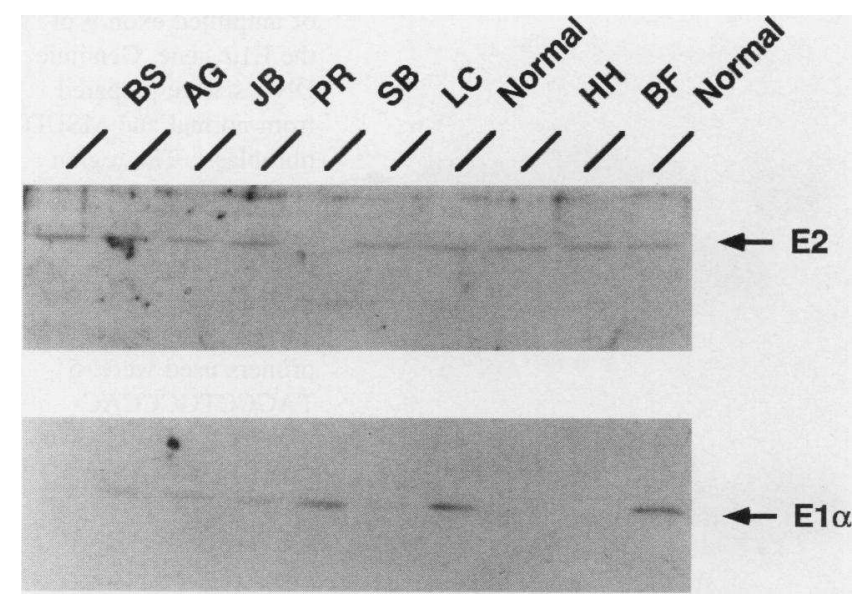

Figure 1. Western blotting of lysates prepared from normal and MSUD fibroblasts. All lysates were applied to a $10 \%$ SDS polyacrylamide gel at $200 \mu \mathrm{g}$ protein per lane. Separated proteins were electrotransferred to polyvinylidene difluoride membranes. The filters were probed with either E2 (upper panel) or E1 $\alpha$ (lower panel) antibodies radiolabeled by coupling with ${ }^{125}$ I-protein A. MSUD patients B.S., A.G., J.B. and P.R. were of the intermediate phenotype. Patients S.B., L.C., H.H., and B.F. exhibited classic MSUD.

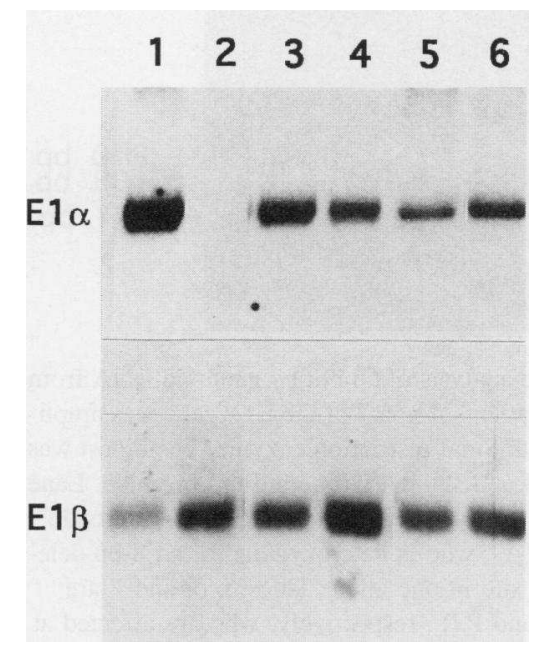

Figure 2. Northern blot analysis of poly $\mathrm{A}^{+}$-enriched RNA from normal and MSUD fibroblasts. The 1.5-kb human E1 $\alpha$ and the murine $\mathrm{E} 1 \beta$ cDNA's were radiolabeled with $[\alpha-32 \mathrm{P}]$ using the Megaprime DNA-labeling system (Amersham Corp., Arlington Heights, IL) (19). Each lane contained $5 \mu \mathrm{g}$ poly $(A)^{+}$RNA except lane 1 , where $1.5 \mu \mathrm{g}$ was applied. Lane 1 , normal subject; Lane 2, A-1. (classic MSUD of Israeli origin); Lane 3, B.S.; Lane 4, P.R.; Lane 5 , A.G.; and Lane 6, J.B.

(lower panel) shows that the $\mathrm{E} 1 \alpha$ subunit is markedly reduced in cells from three intermediate patients A.G., J.B., and P.R. compared with normal. The El $\alpha$ subunit is barely detectable in the fourth intermediate patient B.S. and a classic patient L.C. In contrast, the $\mathrm{E} 1 \alpha$ subunit is present in normal amounts in another classic MSUD patient S.B. The E2 subunit (Fig. 1, upper panel) is present in normal amounts in all MSUD patients except S.B. The results establish that S.B. is affected at the E2 locus. On the other hand, the decreased abundance of $\mathrm{E} 1 \alpha$ subunit in the five MSUD patients studied (A.G., J.B., P.R., B.S., L.C., H.H. and B.F.) only indicate that either E1 $\alpha$ or E1 $\beta$ locus is affected. It has been previously shown by Western blotting that reduced level of either of the two subunits of E1 (E1 $\alpha$ or $\mathrm{E} 1 \beta$ ) caused by a mutation reduces the level of the other normal subunit (20-22).

Northern blotting was performed using poly $(\mathrm{A})^{+}$RNA prepared from normal, a classic MSUD patient from Israel (A-1) and the four intermediate MSUD subjects (B.S., P.R., A.G. and J.B.) from Mexico. The E1 $\alpha$ mRNA is present in normal amounts in the four intermediate MSUD patients (lanes 3-6, Fig. 2, upper panel), and is absent in the classic MSUD patient (lane 2). The $E 1 \beta$ mRNA is present in all MSUD patients (Fig. 2 , lower panel). The reduced signal of $\mathrm{E} 1 \beta$ mRNA in normal (lane 1 , lower panel) was due to the lower amount of poly (A) ${ }^{+}$ RNA applied $(1.5 \mu \mathrm{g})$ compared with the other lanes $(5 \mu \mathrm{g})$. The results show that the mutation of the $\mathrm{E} 1 \alpha$ or $\mathrm{E} 1 \beta$ locus did not affect transcription and stability of either mRNA in the intermediate MSUD, and that reduction in the immunoreactive E1 $\alpha$ subunit is a posttranscriptional event.

Identification of mutations in intermediate MSUD. Previously we identified an 8-bp deletion in exon 7 of the El $\alpha$ gene of an MSUD patient GM-649, which abolishes a SmaI restriction site (18). This change in restriction pattern was used to screen other MSUD patients. Exon 7 was amplified from genomic DNA of 35 known MSUD subjects and digested with SmaI. The digested samples were analyzed on $2 \%$ agarose gels as shown in Fig. 3. Undigested amplified exon 7 from a normal subject was 240-bp in size (lane 2). Digestion of the normal amplified genomic DNA with SmaI produced two smaller 169and 71-bp fragments (lane 3). Digestion of the amplified exon 7 from GM-649, who is heterozygous for 8-bp deletion, resulted 


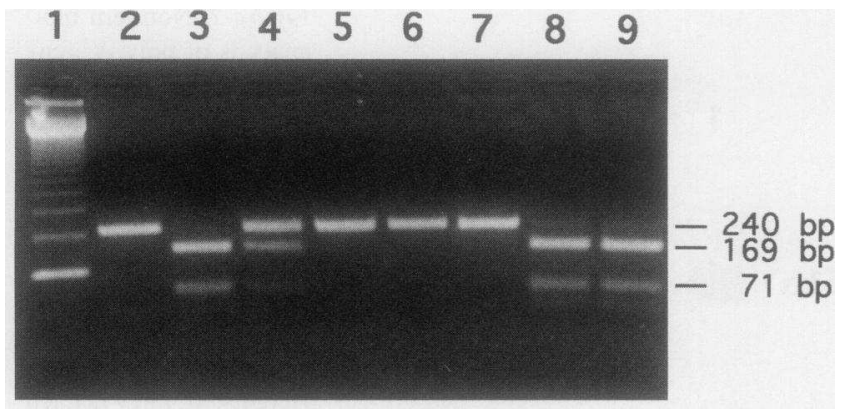

Figure 3. Restriction enzyme analysis of amplified genomic DNA from normal subject and MSUD patients. Exon 7 of the E1 $\alpha$ gene was amplified by PCR and digested with SmaI restriction enzyme. The digest was separated on $2 \%$ agarose gel and stained with ethidium bromide. Lane 1, 123-bp ladder markers; Lane 2, undigested DNA; lane 3, normal digested DNA; lane 4, GM-649, who is heterozygous for an 8-bp deletion that abolishes the SmaI site in one allele; lanes 5, 6, and 7 are MSUD patients A.G., J.B., and P.R., respectively, who are affected at the SmaI site; lanes 8 and 9 are MSUD patients S.B. (intermediate) and P.B. (classic), respectively, who are not affected at the SmaI site.

in three fragments (lane 4). An uncut 240-bp fragment is caused by the absence of the SmaI site secondary to the 8-bp deletion. The other two smaller species are contributed by the other allele, which contains a normal SmaI site in exon 7. Interestingly, amplified DNA from exon 7 of three of the Mexican patients with intermediate MSUD (A.G., J.B. and P.R.) was not cut by SmaI (lanes 5-7). Two other MSUD patients of Mexican origin, B.S. (intermediate) and P.V. (classic), shows a normal restriction pattern of 169-and 71-bp fragments (lanes 8 and 9), which was also observed in 29 other MSUD patients (data not shown).

The absence of the SmaI site in exon 7 in these intermediate patients, A.G., J.B., and P.R., led us to initially speculate that these patients were homozygous for the 8-bp deletion at the E1 $\alpha$ locus. To confirm this, amplified exon 7 from these patients was subcloned into Bluescript plasmid and sequenced. To our surprise, a homozygous $G$ to A transition at base 895 of the E1 $\alpha$ gene (12), instead of an 8-bp deletion, was found at the SmaI site (Fig. 4). The G to A conversion accounts for the abolishment of the SmaI site, and a Gly-245 to Arg substitution $(\mathrm{G} 245 \mathrm{R})$ in the $\mathrm{E} 1 \alpha$ subunit.

Since intermediate patient B.S. showed a normal SmaI digestion pattern, the mutation in this patient does not involve this restriction site. To determine the mutation in B.S., all nine exons of the $\mathrm{E} 1 \alpha$ gene were amplified using flanking intronic primers. Each amplified exon was subjected to analysis by single-stranded conformational polymorphism (SSCP) (23). As shown in Fig. 5 (the upper bands), amplified exon 9 from B.S. (lane 2) has a distinct shift in mobility, compared to a normal (lane 1) and two other classic MSUD patients B.F. (lane 3) and H.H. (lane 4) that also had normal mobility. Lanes 5 and 6 are two patients (K.U. and B.A.), who are heterozygous for the Y393N mutation in exon 9, which resulted in a doublet in the upper band as indicated by the arrows.

The results of SSCP indicated that intermediate patient B.S. is homozygous for a mutation in exon 9 . Direct sequencing of amplified exon 9 using ${ }^{32} \mathrm{P}$-end labeled primers was carried out with a normal and three MSUD patients (B.S., B.F., and K.U.). To facilitate detection of the mutation, the sequencing samples

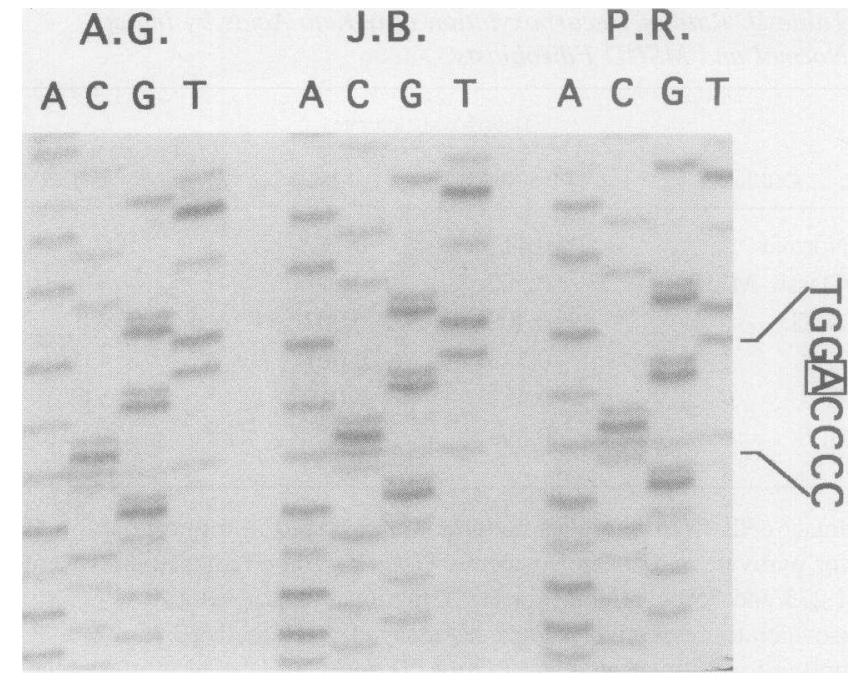

Figure 4. Nucleotide sequencing showing the $\mathrm{G}$ to $\mathrm{A}$ mutation in exon 7 of the E1 $\alpha$ gene of intermediate MSUD patients A.G., J.B., and P.R. PCR amplified exon 7 from the three patients were subcloned into pBS plasmid vector (Stratagene, La Jolla, CA) and sequenced with the antisense primer 5'-GTCAGTGCTGTGGGGATGCT-3'. The boxed nucleotide depicts the homozygous $\mathrm{G}$ to $\mathrm{A}$ transition in the three intermediate MSUD patients. The base change (underlined) abolishes the SmaI site by altering the recognition sequence from CCCGGG to CCCAGG.

were applied to a polyacrylamide gel according to the four nucleotide groups A, C, G and T (Fig. 6). Intermediate patient B.S. shows a distinct homozygous $\mathrm{T}$ to $\mathrm{G}$ transversion at base 1253 of the E1 $\alpha$ gene (12) (see column G and T). The mutation results in a Phe-364 to Cys substitution (F364C) in the E1 $\alpha$ subunit.

Characterization of the G245R and F364C mutations. The

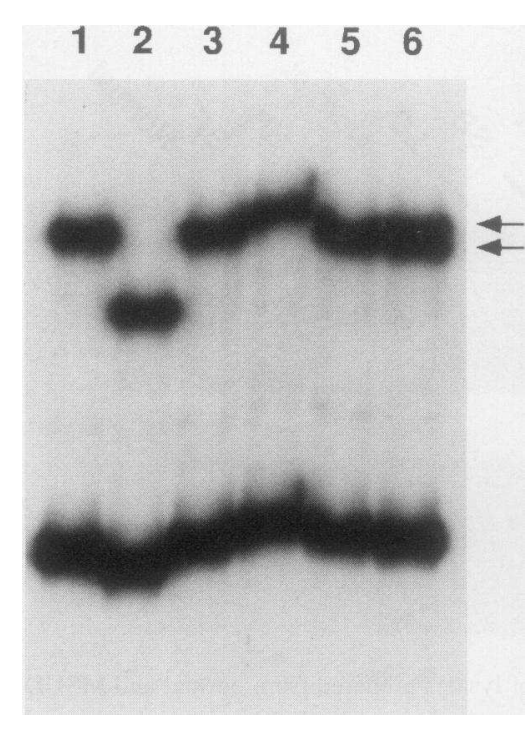

Figure 5. SSCP analysis of amplified exon 9 of the El $\alpha$ gene. Genomic DNA's were prepared from normal and MSUD fibroblasts. The region encompassing the entire coding region of exon 9 of the $\mathrm{E} 1 \alpha$ gene was amplified using ${ }^{32} \mathrm{P}$-dCTP as a labeled nucleotide. The primers used were: $5^{\prime}$ TAGCCTGCCCACTGCCCCATGT-3' (intron 8 ) ( sense) and 5' TCTCGGGGTACCTGAGGATGG-3' (bases 1408-1388) (antisense). SSCP analysis was carried as described under Methods. Lane 1, normal; lane 2, B.S. (intermediate

MSUD patient); lanes 3 and 4, B.F. and H.H., respectively, who are classic patients; lanes 5 and 6, K.U. and B.A., respectively, who are heterozygous for the Y393N mutation in exon 9. The arrows indicate the doublet in lanes 5 and 6 . 

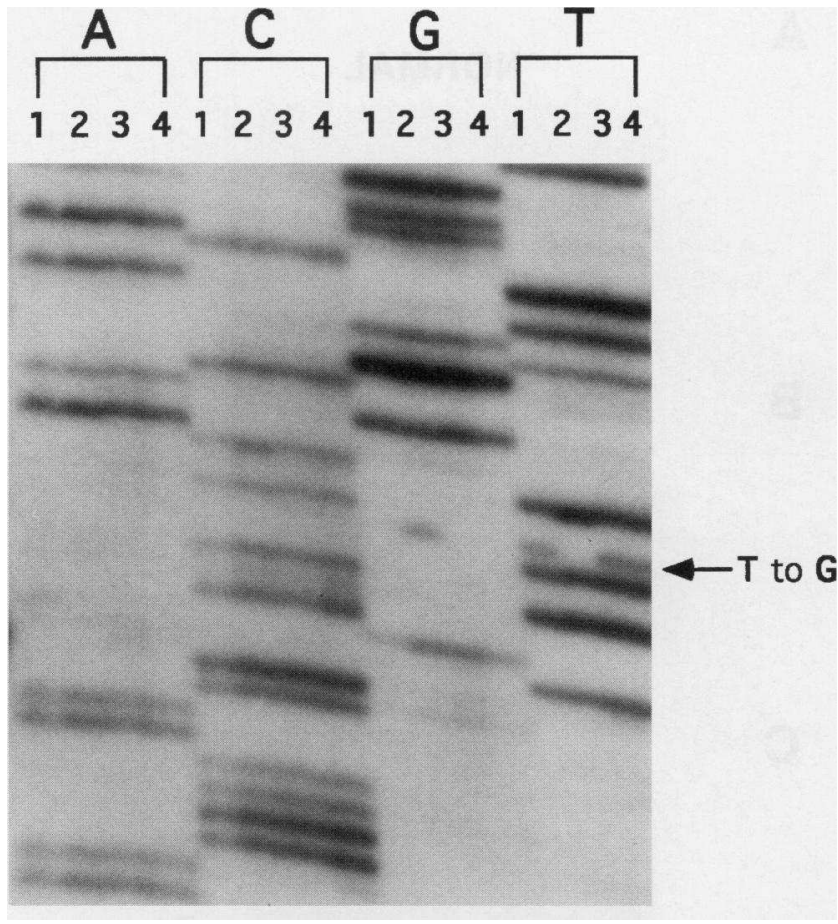

Figure 6. Direct sequencing of amplified exon 9 DNA fragment. Sequencing samples of normal and MSUD patients were applied in groups according to the nucleotides $\mathrm{A}, \mathrm{C}, \mathrm{G}$, and T. Under each nucleotide, lane 1, normal; lane 2, intermediate patient B.S.; lanes 3 and 4, classic MSUD patients B.F. and K.U., respectively. The $\mathrm{T}$ to $\mathrm{G}$ transversion in B.S. is indicated by an arrow.

G245R and F364C mutations were introduced into the normal E1 $\alpha$ cDNA by site-directed mutagenesis, and the mutations were confirmed by DNA sequencing. The entire E1 $\alpha$ cDNA containing either mutation was inserted into the EBO expression vector for transient expression studies. The plasmids carrying the normal and the mutant E1 $\alpha$ cDNAs were transfected into E1 $\alpha$ deficient lymphoblasts from a Mennonite classic MSUD patient (LMK). LMK cells are homozygous for the Y393N substitution in the E1 $\alpha$ subunit (24). Intact untransfected and transfected lymphoblasts were used to measure the rate of decarboxylation of $\alpha$-keto [1- ${ }^{14} \mathrm{C}$ ] isovalerate. Fig. 7 shows that untransfected normal lymphoblasts have substantial (100\%) enzyme activity, (lane 1), and that LMK cells transfected with the EBO vector without insert (lane 2) exhibited trace or no decarboxylase activity. Transfection of LMK cells with vector containing the normal E1 $\alpha$ cDNA (lane 3 ) restored decarboxylation activity to $72 \%$ of normal. LMK cells transfected with vector containing the G245R mutation in E1 $\alpha$ cDNA produced a slight but reproducible (5\%) decarboxylation of the $\alpha$-keto acid. Transfection of LMK cells with vector containing the E1 $\alpha$ cDNA with the F364C substitution was unable to decarboxylate $\alpha$-ketoisovalerate. The results establish that the G245R and F364C alterations produce defective $\mathrm{E} 1 \alpha$ polypeptides, and are the cause of the intermediate MSUD phenotype.

Lysates prepared from untransfected normal lymphoblasts and from transfected LMK lymphoblasts were analyzed by Western blotting (Fig. 8). Specific antibodies against either $\mathrm{E} 1 \alpha$ or $\mathrm{E} 1 \beta$ subunits were used as probes. LMK cells untransfected or transfected with EBO vectors without inserts showed reduced levels of the E1 $\alpha$ subunit, compared to normal

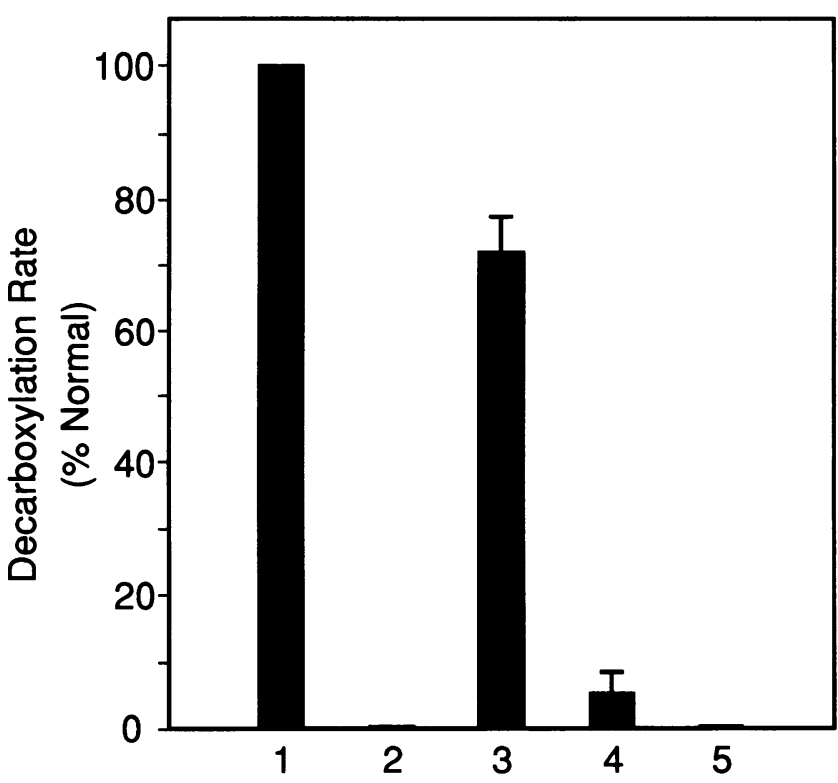

Figure 7. Decarboxylation of $\alpha$-keto $\left[1-{ }^{14} \mathrm{C}\right]$ isovalerate by untransfected normal lymphoblasts and transfected El $\alpha$-deficient lymphoblasts (LMK). The EBO vector without insert (lane 2) or carrying normal (lane 3), G245R (lane 4) or F364C (lane 5) E1 $\alpha$ cDNAs was transfected into LMK cells as described previously (8). Untransfected normal and hygromycin-selected transfected LMK cells were analyzed for decarboxylation activity by the intact cell assay using $\alpha$-keto [1-

${ }^{14} \mathrm{C}$ ] isovalerate as substrate $(10)$. The results are expressed as percent of activity in normal untransfected cells $\left(100 \%\right.$ or $0.288 \mathrm{nmol} \mathrm{CO}^{2} /$ $\mathrm{min} / \mathrm{mg}$ protein) (lane 1$)$. Each bar represents mean $\pm \operatorname{SEM}(n=6)$.

untransfected cells (Fig. 8, upper panel). LMK cells transfected with vector harboring normal E1 $\alpha$ cDNA increased the E1 $\alpha$ subunit to a level similar to normal, but with the appearance of a smaller proteolytic fragment (E1 $\left.\alpha^{*}\right)$. (Fig. 8, upper panel). A similar increase in E1 $\alpha$ subunit was observed in LMK cells transfected with the five mutant E1 $\alpha$ cDNAs (Fig. 8, upper panel). G245R and F364C in E1 $\alpha$ are the subjects of the current study. N222S and R220W in E1 $\alpha$ encoded by exon 6 are mutations in the putative TPP-binding pocket. T265R in E1 $\alpha$ encoded by exon 7 is a mutation in the putative subunit interaction region (Chuang, J. L., D. T. Chuang, and R. P. Cox, unpublished results). The LMK cells transfected with vector having a normal, N222S or R220W E1 $\alpha$ cDNAs restored the E1 $\beta$ subunit to approximately half the normal level (Fig. 8, lower panel). The results indicates that mutant $\mathrm{E} 1 \alpha$ subunits containing the N222S or R220W mutation are able to assemble with endogenous $\mathrm{E} 1 \beta$, similar to normal $\mathrm{E} 1 \alpha$. The mutant $\mathrm{E} 1$ proteins containing these mutations have markedly reduced E1 enzymatic activity (data not shown). LMK cells untransfected or transfected with the EBO vector without inserts showed trace amounts of the E1 $\beta$ subunit (Fig. 8, lower panel). Transfection of LMK cells with vector containing the G245R E1 $\alpha$ cDNA restored $\mathrm{E} 1 \beta$ to $\sim 20-30 \%$ of that transfected with normal E1 $\alpha$ cDNA. In LMK cells transfected with the F364C and T265R cDNA, the $\mathrm{E} 1 \beta$ subunit remained in trace amounts, indicating the absence of assembly between the mutant E1 $\alpha$ and normal E1 $\beta$ (Fig. 8, lower panel).

Altered kinetics of E1 assembly caused by G245R and F364C mutations. The reduced ability of transfected G245R 


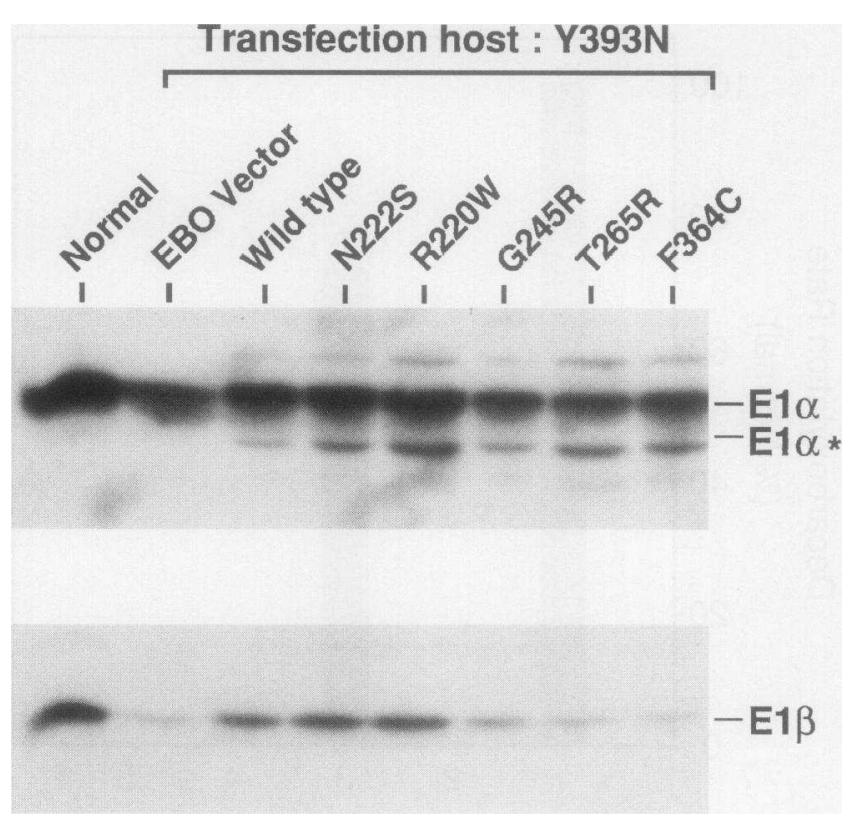

Figure 8. Western blotting of lysates from normal and transfected E1 $\alpha$ deficient LMK lymphoblasts. LMK cells were transfected with EBO vector without insert or carrying normal, N222S, R220W, G245R, T265R, or F364C mutant El $\alpha$ cDNAs (see text for these mutations). The lysates were prepared from untransfected normal and transfected cell and were subjected to SDS-PAGE, with each lane containing 200 $\mu \mathrm{g}$ protein. Proteins were electrotransferred to polyvinylidene difluoride membranes. The filters were probed with either E1 $\alpha$ (upper panel) or E1 $\beta$ (lower panel) antibodies radiolabeled by coupling with ${ }^{125}$ I-protein $\mathrm{A}$. E1 $\alpha^{*}$ represents proteolytic products.

and $\mathrm{F} 364 \mathrm{C} \mathrm{E} 1 \alpha$ to restore $\mathrm{E} 1 \beta$ in LMK cells compared with normal $\mathrm{E} 1 \alpha$, strongly suggests that, in addition to causing enzyme dysfunction, these mutations impair E1 assembly. To investigate the kinetics of $\mathrm{E} 1 \alpha$ and $\mathrm{E} 1 \beta$ assembly, we have developed a method for pulse-chase labeling of E1 subunits in an $E$. coli host. ES ${ }^{\text {ts }} E$. coli cells were doubly transformed with a Histagged E1 expression vector carrying either normal or mutant His-tagged E1 $\alpha$ cDNA and normal untagged E1 $\beta$ cDNA, as well as a second vector pGroESL that over-expresses bacterial chaperonin proteins GroEL and GroES. The cells were heatshocked at $42^{\circ} \mathrm{C}$ for $4 \mathrm{~h}$, followed by induction at $37^{\circ} \mathrm{C}$ with IPTG for $5 \mathrm{~min}$. The cells were pulsed with $\left[{ }^{35} \mathrm{~S}\right]$ cysteine/ $\left[{ }^{35} \mathrm{~S}\right]$ methionine for $1 \mathrm{~min}$ and chased with the corresponding nonradioactive amino acids. Samples were taken at different intervals from 2 min to $120 \mathrm{~min}$, and lysates purified by $\mathrm{Ni}^{2+}$ NTA affinity chromatography. The eluted radioactive peptides were analyzed by SDS-PAGE and autoradiograms obtained by fluorography. Since E1 $\beta$ is untagged, its copurification with His-tagged $\mathrm{E} 1 \alpha$ is an indication of assembly of the two polypeptides. Fig. $9 \mathrm{~A}$ shows that the assembly of radioactively labeled $\mathrm{E} 1 \beta$ with labeled normal E1 $\alpha$ occurs as early as $10 \mathrm{~min}$ after the chase, approaching a plateau in $40 \mathrm{~min}$. The level of the normal labeled His-tagged El $\alpha$ remains relatively constant during the $2 \mathrm{~h}$ chase. The assembly of normal E1 $\beta$ with the labeled G245R E1 $\alpha$ appears to be slower than normal E1 $\alpha$. The level of associated $\mathrm{E} 1 \beta$ is clearly much lower than that observed in the normal $\mathrm{E} 1 \alpha$, and reached a plateau at $60 \mathrm{~min}$ after the chase (Fig. $9 \mathrm{~B}$ ). In contrast, there was no significant assembly of

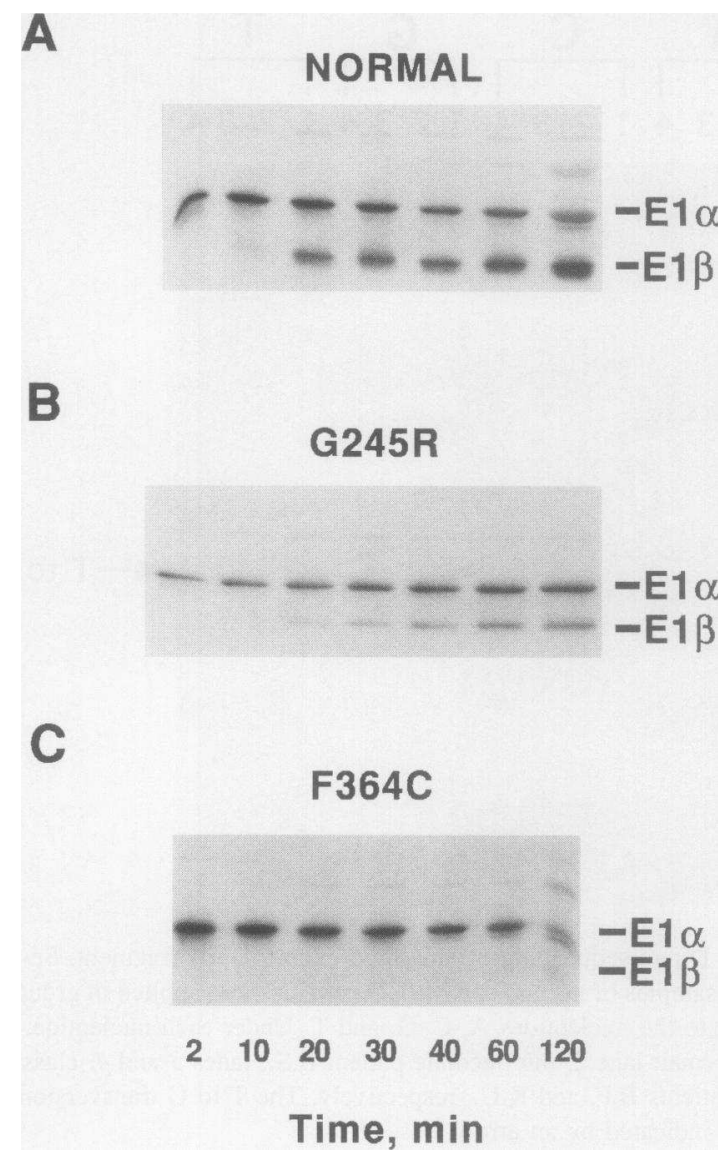

Figure 9. Pulse-chase labeling autoradiogram showing the kinetics of assembly of normal and mutant His-tagged $\mathrm{E} 1 \alpha$ with untagged $\mathrm{E} 1 \beta$. The bacterial expression system containing overexpressed GroEL and GroES and the pulse-chase of E1 subunits are described under Methods. Cell lysates containing ${ }^{35} \mathrm{~S}$-labeled polypeptides were bound to $\mathrm{Ni}^{2+}$. NTA resin, washed and eluted with an SDS sample buffer (16). The eluted labeled polypeptides were analyzed by SDS-PAGE followed by fluorography. Assembly at different time points $(2-120 \mathrm{~min})$ of the untagged $\mathrm{E} 1 \beta$ with the His-tagged normal or mutant $\mathrm{E} 1 \alpha$ resulted in the copurification of both subunits as shown in the autoradiograms. $(A)$ Normal His-tagged E1 $\alpha ;(B)$ G245R His-tagged E1 $\alpha ;(C)$ F364C Histagged E1 $\alpha$.

labeled $\mathrm{E} 1 \beta$ with His-tagged mutant F364C E1 $\alpha$ during the 2 $\mathrm{h}$ chase. This was indicated by the absence of the copurified $\mathrm{E} 1 \beta$, while the signal of His-tagged $\mathrm{E} 1 \alpha$ remained relatively constant (Fig. $9 \mathrm{C}$ ). These results indicate that both G245R and $\mathrm{F} 364 \mathrm{C}$ mutations reduce the rate of assembly of mutant E1 $\alpha$ with normal $\mathrm{E} 1 \beta$.

Reduced or undetectable activity of mutant E1 proteins. Prolonged growth of $E$. coli with IPTG induction at $37^{\circ} \mathrm{C}$ for $15 \mathrm{~h}$ resulted in the production of reduced but significant amounts of assembled mutant His-tagged E1 proteins carrying G245R or F364C mutations in E1 $\alpha$, compared with normal. Both normal and mutant His-tagged E1 proteins were purified by $\mathrm{Ni}^{2+}$ NTA affinity column and eluted with a 15 to $250 \mathrm{mM}$ imidazole gradient ( $\mathrm{pH} \mathrm{7.5)}$. The final yield was $50 \mathrm{mg} / 1 \mathrm{cul}-$ ture for normal E1 protein, $8 \mathrm{mg} / 1$ culture for G245R mutant $\mathrm{E} 1$ and $6 \mathrm{mg} / \mathrm{l}$ culture for F364C mutant E1. Activity of normal and mutant $\mathrm{E} 1$ proteins was assayed by a radiochemical method using $\alpha$-keto $\left[1-{ }^{14} \mathrm{C}\right]$ isovalerate as a substrate and 2,6-dichloro- 
phenolindolphenol as an artificial electron acceptor. Recombinant normal E1 protein showed specific activity of $87.3 \pm 13.7$ nmol $\mathrm{CO}_{2} / \mathrm{min} / \mathrm{mg}$ protein $(n=3)$ and $\mathrm{G} 245 \mathrm{R}$ mutant E1 protein exhibited specific activity of $2.32 \pm 0.14 \mathrm{nmol} \mathrm{CO} / \mathrm{min} /$ mg protein $(n=3)$. F364C mutant E1 protein had no measurable activity. The specific activity of G245R mutant E1 protein was $2.7 \%$ of normal.

\section{Discussion}

This is the first detailed molecular and biochemical characterization of intermediate MSUD. Previous studies were predominantly of the classic form of the disease because of its prevalence among MSUD patients and the severity of its presentation. On the other hand, intermediate MSUD is milder and often later in presentation, and as a result is understudied. It is of interest that BCKAD activity of intermediate patient B.S. is at the level of classic MSUD, but her phenotype is distinctly of the intermediate type. Other studies have also noted a poor correlation of residual $\mathrm{BCK} A \mathrm{D}$ complex activity with the clinical phenotype (25). These findings suggest that the individual's genotype may modulate the severity of disease. Alternatively, the enzyme activity in a patient's hepatocytes may not be accurately reflected in fibroblast or lymphoblast cultures. The BCKAD complex is $30-50 \%$ dephosphorylated or active in fibroblasts $(10,26)$, whereas it is nearly $100 \%$ dephosphorylated or active in the liver (27). In addition, activities of the totally dephosphorylated BCKAD complex in several tissues (liver, kidney, and heart) are higher than in fibroblasts (28). The presence of residual activity in various tissues of intermediate MSUD patients may be sufficient under certain physiological conditions to ameliorate clinical manifestations. For example, in response to changes in dietary protein or increased catabolism (e.g., starvation), levels of hepatic BCKAD subunits increase a few fold (Chinsky, J. M., unpublished results) (29). Unfortunately, tissues other than fibroblasts and lymphoblasts from these intermediate patients were unavailable for testing. It should be pointed out that patient B.S. had the most severe neurological damage and the highest plasma leucine levels of the four intermediate MSUD patients described. However, she was also diagnosed later than the other three intermediate patients. The results underscore the importance of newborn screening and early dietary therapy for intermediate MSUD.

It is noteworthy that all of the three intermediate MSUD patients that are homozygous for the G245R mutation are of Hispanic-Mexican origin. Homozygosity in MSUD is relatively rare except for the Y393N Mennonite mutation where the Founder effect is responsible (30). Analysis of 31 non-Mexican patients showed that these subjects did not have the G245R mutation. Although relatedness and consanguinity were denied by their families, two of the intermediate patients, who are homozygous for the G245R mutation, were from the Monterey area of Mexico and the third was from Southern Mexico. It is possible that the three apparently unrelated families inherited this mutation from a common ancestor. More intermediate MSUD families of Hispanic origin need to be studied to determine the prevalence of the G245R allele in the Mexican population. There is a high frequency of MSUD in Spain $(1 / 12,000$ to $1 / 50,000$ ) (31) compared with the estimated worldwide prevalence of $1 / 180,000$ (32). The increased incidence of MSUD in Spain suggests a possible ethnic source for these mutations. The fourth Mexican patient is homozygous for the
F364C mutation. She is the progeny of a 14-yr-old primigravida, so the significance of this homozygosity is uncertain.

Functional analysis of MSUD mutations cannot be carried out by overexpression of the affected subunit in a normal host, where multiple copies of all six distinct polypeptides are present. In the present study, we used an E1 $\alpha$-deficient lymphoblasts host from a Mennonite patient homozygous for the Y393N mutation in the E1 $\alpha$ subunit (24). Transfection with a replication-competent EBO vector carrying the full-length normal El $\alpha$ cDNA resulted in overexpression of the E1 $\alpha$ subunit. However, only a near normal range of decarboxylation activity is restored in the host cells (Fig. 7). The data suggest that the assembly of recombinant normal $\mathrm{E} 1 \alpha$ with endogenous normal $\mathrm{E} 1 \beta$ subunits is limiting as will be discussed later. A partial (5\%) restoration of decarboxylation activity was observed, when the G245R E1 $\alpha$ cDNA was transfected into LMK cells. This rate is similar to the residual (4.0-5.6\%) activity in cultured fibroblasts from the intermediate MSUD patients, who are homozygous for this mutation. The lack of restoration of decarboxylation activity by transfection with F364C E1 $\alpha$ cDNA also agrees with the absence of decarboxylation measured with cultured fibroblasts from the homozygous patient B.S. The concordance between the transfection results and assays of patient's cultured fibroblasts indicates the fidelity of the EBO expression system.

The LMK host cells used in transfection studies contain reduced levels of the $\mathrm{Y} 393 \mathrm{~N}$ mutant $\mathrm{E} 1 \alpha$ subunit and trace amounts of the normal $\mathrm{E} 1 \beta$ subunit (8). The homozygous Y393N E1 $\alpha$ mutation was shown to impede assembly of that subunit with normal $\mathrm{E} 1 \beta$ subunits. Unassembled $\mathrm{E} 1 \alpha$ and in particular $\mathrm{E} 1 \beta$ subunits are not stable and are degraded in cells $(20,22)$. It is perplexing that transfection of LMK cells with normal $\mathrm{E} 1 \alpha$ cDNA restores the $\mathrm{E} 1 \beta$ subunit to only $50 \%$ of normal level (Fig. 8.). Since the EBO vector overexpresses normal $\mathrm{E} 1 \alpha$ subunits, one would expect that the $\mathrm{E} 1 \beta$ level is restored to normal through assembly with recombinant El $\alpha$. Competition between the endogenous Y393N and the transfected normal $\mathrm{E} 1 \alpha$ subunits for assembly with $\mathrm{E} 1 \beta$ is unlikely because the host mutant $\mathrm{E} 1 \alpha$ subunit is assembly-incompetent. A plausible explanation is that only a portion of the transfected normal E1 $\alpha$ subunit in the LMK cell is properly folded, and capable of assembly with E1 $\beta$. Recent studies have firmly established that molecular chaperones, most of them heat-shock proteins (Hsp), play an essential role in the biogenesis of mitochondrial proteins (33). In mitochondria of transfected LMK cells, chaperone proteins Hsp60 and Hsp10 may be limiting, resulting in reduced levels of assembly-competent recombinant E1 $\alpha$ subunits. The current model for chaperone-mediated mitochondrial import is that the nascent polypeptides, while still associated with the ribosome, bind to the cytosolic Hsp70 to maintain the unfolded and import-competent state. Once imported into the mitochondrial matrix, the unfolded mature polypeptide initially interacts with mitochondrial Hsp70, and is then transferred to the Hsp60/Hsp10 complex of this organelle. The latter complex provides a scaffold for proper folding of the mature polypeptide to occur through multiple cycles of ATP hydrolysis-dependent reactions $(33,34)$.

The pulse-chase labeling studies in $E$. coli represents a novel approach to measure the initial rates of $\mathrm{E} 1 \alpha$ and $\mathrm{E} 1 \beta$ subunit assembly. Development of this method is based on the thesis that the bacterial cells are analogous to the mitochondrial matrix in the folding and assembly of mature mitochondrial polypeptides. The molecular chaperones that participate in the biogene- 
sis of mitochondrial proteins are conserved in E. coli (33). We have shown previously that overexpression of the bacterial chaperones GroEL and GroES, which are homologues of Hsp60 and Hsp10, respectively, in $\mathrm{ES}^{\text {ts }} E$. coli (CG-712) increased the specific activity of E1 by 500 -fold (15). Expression and assembly of E1 in wild-type $E$. coli is very low in the absence of overexpressed chaperones (9). The overproduction of GroEL and GroES was achieved through cotransformation with the pGroESL plasmid. The latter plasmid encodes these chaperones under the regulation of a heat-shock sensitive element and an IPTG-inducible promoter. The double-transformation overexpression is adapted in the pulse-chase labeling studies with the pHisT-hE1 plasmid that encodes both His-tagged E1 $\alpha$ and untagged $\mathrm{E} 1 \beta$ as the second vector. The bacterial overexpression system may not completely duplicate the situation in mammalian cells. Nonetheless, it offers a useful method to dissect, under efficient ex vivo conditions, the effect of certain natural human mutations on chaperone-mediated folding and assembly of mammalian proteins.

Isolation of the His-tagged E1 $\alpha /$ untagged $\mathrm{E} 1 \beta$ subunit complex by nickel affinity column chromatography represents the association of the pulse-labeled nascent chains (Fig. 9). No attempt was made to distinguish assembly intermediates from the final $\alpha_{2} \beta_{2}$ heterotetramers. Using this optimal overexpression system in $E$. coli, we were able to demonstrate altered kinetics of E1 assembly in intermediate MSUD. The slower than normal kinetics observed with the G245R mutation confirm the partial assembly defect deduced from the transfection studies. The absence of significant assembly of the His-tagged mutant F364C E1 $\alpha$ subunit with the normal E1 $\beta$ subunit during the $2 \mathrm{~h}$ chase supports the severe assembly incompetence associated with this mutation. The crystal structure of $\mathrm{E} 1$ has not been determined, but the conserved Gly-245 is in the putative subunit interaction region based on sequence alignment of $\mathrm{E} 1 \alpha$ subunits (35). Chou-Fasman prediction (36) indicates that Gly-245 in the E1 $\alpha$ subunit occurs at a turn preceding a Pro at position 246. The G245R substitution may alter the conformation of the turn, thereby adversely affecting the binding of the E1 $\alpha$ to $\mathrm{E} 1 \beta$ subunit. Phe-364 is situated in the carboxy-terminal region encoded by exon 9 of the E1 $\alpha$ gene. This segment is also highly conserved between $\mathrm{E} 1 \alpha$ subunits of different $\alpha$-keto acid dehydrogenase complexes, however, no function has been assigned to this carboxy-terminal region. We have shown that, in addition to F364C, two other known mutations Y393N $(9,24)$ and Y368C (18) encoded by exon 9 were also defective in E1 assembly. These findings strongly suggest that the exon 9 encoded carboxy-terminal residues are critical for $\mathrm{E} 1 \alpha$ and $\mathrm{E} 1 \beta$ subunit interaction.

Finally, sustained growth ( $15 \mathrm{~h}$ ) of transformed $E$. coli with IPTG induction results in production of reduced but significant amounts of G245R and F364C mutant E1 proteins compared with normal. The data indicate that the individual mutant $\mathrm{E} 1 \alpha$ and normal $\mathrm{E} 1 \beta$ subunits are stable in $E$. coli cotransformed with chaperonins GroEL and GroES, and eventually assemble into mutant heterotetramers. The low or undetectable activity of recombinant $\mathrm{G} 245 \mathrm{R}$ and $\mathrm{F} 354 \mathrm{C}$ mutant $\mathrm{E} 1$ proteins provides direct evidence that both mutations in E1 $\alpha$ disrupt the catalytic function of the assembled heterotetramers, in addition to the slow rates of assembly. The impaired E1 activity is consistent with the reduced or absent decarboxylation of BCKA observed in patients' fibroblasts (Table II) and in the transfection studies (Fig. 7). Moreover, the deficiency of E1 activity is apparently responsible for dysfunction of the $\mathrm{BCKAD}$ complex in the intermediate MSUD patients.

\section{Acknowledgments}

This work was supported by grants DK-26758 and DK-37373 from the National Institutes of Health, grant 1-1149 from the March of Dimes Birth Defects Foundation, and a grant from the Life and Health Insurance Medical Research Fund. J. R. D. is a Medical Scientist Trainee supported by grant 5-P32GM-08014 from the National Institutes of Health and by the Perot Family Foundation.

\section{References}

1. Chuang, D. T., and V. E. Shih. 1994. Disorders of branched chain amino acid and keto acid metabolism. In The Metabolic and Molecular Basis of Inherited Disease, 7th edition. C. R. Scriver, A. L. Beaudet, W. S. Sly, and D. Valle, editors. McGraw-Hill Inc., New York. 1239-1278.

2. Danner, D. J., and L. J. Elsas. 1989. Disorders of branched-chain amino acid and ketoacid metabolism. In The Metabolic Basis of Inherited Disease, 6th edition. C. R. Scriver, A. L. Beaudet, W. S. Sly, and D. Valle, editors. McGrawHill Inc., New York. 671-692.

3. Taylor, J., B. H. Robinson, and W. G. Sherwood. 1978. A defect in branched-chain amino acid metabolism in a patient with congenital lactic acidosis due to dihydrolipoyl dehydrogenase deficiency. Pediatr. Res. 12:60-62.

4. Pettit, F. H., S. J. Yeaman, and L. J. Reed. 1978. Purification and characterization of branched-chain $\alpha$-keto acid dehydrogenase complex of bovine kidney. Proc. Natl. Acad. Sci. USA. 75:4881-4885.

5. Yeaman, S. J. 1989. The 2-oxo acid dehydrogenase complexes: recent advances. Biochem. J. 247:625-632.

6. Harris, R. A., R. Paxton, S. M. Powell, G. W. Goodwin, M. J. Kuntz, and A. C. Han. 1986. Regulation of branched-chain a-ketoacid dehydrogenase complex by covalent modification. Adv. Enzyme Regul. 25:219-237.

7. Lindsay, J. G. 1989. Targeting of 2-oxo acid dehydrogenase complexes to the mitochondrion. Ann. N.Y. Acad. Sci. 573:254-266.

8. Fisher, C. R., J. L. Chuang, R. P. Cox, C. W. Fisher, R. A. Star, and D. T. Chuang. 1991. Maple syrup urine disease in Mennonites. Evidence that the Y393N mutation in El $\alpha$ impedes assembly of the E1 component of branched-chain $\alpha$ keto acid dehydrogenase complex. J. Clin. Invest. 88:1034-1037.

9. Davie, J. R., R. M. Wynn, R. P. Cox, and D. T. Chuang. 1992. Expression and assembly of a functional E1 component $\left(\alpha_{2} \beta_{2}\right)$ of mammalian branchedchain $\alpha$-ketoacid dehydrogenase complex in Escherichia coli. J. Biol. Chem. 267:16601-16606.

10. Chuang, D. T., and R. P. Cox. 1988. Enzyme assays with mutant cell lines of maple syrup urine disease. Methods Enzymol. 166:135-146.

11. Margolskee, R. F., P. Kavathas, and P. Berg. 1988. Epstein-Barr virus shuttle vector for stable episomal replication of cDNA expression libraries in human cells. Mol. Cell. Biol. 8:2837-2847.

12. Chuang, J. L., R. P. Cox, and D. T. Chuang. 1993. Characterization of the promoter-regulatory region and structural organization of the $\mathrm{E} 1 \alpha$ gene (BCKDHA) of human branched-chain $\alpha$-keto acid dehydrogenase complex. $J$. Biol. Chem. 268:8309-8316.

13. Wynn, R. M., J. L. Chuang, J. R. Davie, C. W. Fisher, M. A. Hale, R. P. Cox and D. T. Chuang. 1992. Cloning and expression in Escherichia coli of mature E1 $\beta$ subunit of bovine mitochondrial branched-chain $\alpha$-keto acid dehydrogenase complex. Mapping of the E1 $\beta$-binding region on E2. J. Biol. Chem. 267:18811889.

14. Goloubinoff, P., A. A. Gatenby, and G. H. Lorimer. 1989. GroE heatshock proteins promote assembly of foreign prokaryotic ribulose bisphosphate carboxylase oligomers in Escherichia coli. Nature (Lond.). 337: 44-47.

15. Wynn, R. M., J. R. Davie, R. P. Cox, and D. T. Chuang. 1992. Chaperonins GroEL and GroES promote assembly of heterotetramers $\left(\alpha_{2} \beta_{2}\right)$ of mammalian mitochondrial branched-chain $\alpha$-keto acid decarboxylase in Escherichia coli. J. Biol. Chem. 267:12400-12403.

16. Guzman-Verduzco, L.-M., and Y. M. Kupersztoch. 1987. Fusion of Esche richia coli heat-stable enterotoxin and heat-labile enterotoxin $\beta$ subunit. J. Bacteriol. 169:5201-5208.

17. Laemmli, U. K. 1970. Cleavage of structural proteins during the assembly of the head of bacteriophage T4. Nature (Lond.). 227:680-685.

18. Chuang, J. L., C. R. Fisher, R. P. Cox, and D. T. Chuang. 1994. Molecular basis of maple syrup urine disease: Novel mutations at the E1 $\alpha$ locus that impairs E1 $\left(\alpha_{2} \beta_{2}\right)$ assembly or decrease steady-state E1 $\alpha$ mRNA levels of branched-chain $\alpha$-keto acid dehydrogenase complex. Am. J. Hum. Genet. 55:297-304.

19. Chinsky, J. M., and P. A. Costeas. 1993. Molecular cloning and analysis of the expression of the E1 $\beta$ subunit of branched chain $\alpha$-ketoacid dehydrogenase in mice. Biochem. Biophys. Acta. 1216:499-503. 
20. Fisher, C. W., J. L. Chuang, T. A. Griffin, K. S. Lau, R. P. Cox, and D. T Chuang. 1989. Molecular phenotypes in cultured maple syrup urine disease cells: Complete E1 $\alpha$ cDNA sequence and mRNA and subunit contents of the human branched-chain $\alpha$-keto acid dehydrogenase complex. J. Biol. Chem. 264:34483453.

21. Zhang, B., H. J. Edenberg, D. W. Crabb, and R. A. Harris. 1989. Evidence for both a regulatory mutation and a structural mutation in a family with maple syrup urine disease. J. Clin. Invest. 83:1425-1429.

22. Nobukuni, Y., H. Mitsubuchi, I. Akaboshi, Y. Indo, F. Indo, A. Yoshioka, and I. Matsuda. 1991. Maple syrup urine disease. Complete defect of the E1 $\beta$ subunit of the branched chain $\alpha$-ketoacid dehydrogenase complex due to a deletion of an 11-bp repeat sequence which encodes a mitochondrial targeting leader peptide in a family with the disease. J. Clin. Invest. 87:1862-1866.

23. Orita, M., L. H. Iwahana, H. Kanazawa, K. Hayashi, and T. Seikiya. 1989 Detection of polymorphisms of human DNA by gel electrophoresis as singlestrand conformation polymorphisms. Proc. Natl. Acad. Sci. USA. 86:2766-2770

24. Fisher, C. R., C. W. Fisher, D. T. Chuang, and R. P. Cox. 1991. Occurrence of a Tyr393 $\rightarrow$ Asn (Y393N) mutation in the E1 $\alpha$ gene of the branched-chain $\alpha$ keto acid dehydrogenase complex in maple syrup urine disease patients from a Mennonite population. Am. J. Hum. Genet. 49:429-434.

25. Gonzales-Rios, M. C., D. T. Chuang, R. P. Cox, K. Schmidt, K. Knopf and S. A. Packman. 1985. A distinct variant of intermediate maple syrup urine disease. Clin. Genet. 27:153-159.

26. Tashima, K., Y. Kuroda, I. Yokota, E. Naito, M. Ito, T. Watanabe, E. Takeda, and M. Miyao. 1985. Activation of branched-chain $\alpha$-ketoacid dehydrogenase complex by $\alpha$-chloroisocaproate in normal and enzyme-deficient fibroblasts Clin. Chim. Acta. 147:103-108.

27. Gillim, S. E., R. Paxton, G. A. Cook, and R. A. Harris. 1983. Activity state of the branched chain $\alpha$-ketoacid dehydrogenase complex in heart, liver and kidney of normal, fasted, diabetic and protein-starved rats. Biochem. Biophys. Res. Commun. 111:74-81.

28. Harper, A. E., R. H. Miller, and K. P. Block. 1984. Branched-chain amino acid metabolism. Ann. Rev. Nutr. 4:409-454.

29. Zhao, Y., K. M. Popov, Y. Shimomura, N. Y. Kedishvili, J. Jaskiewicz, M. J. Kuntz, J. Kain, B. Zhang, and R. A. Harris. 1994. Effect of dietary protein on the liver content and subunit composition of the branched-chain $\alpha$-ketoacid dehydrogenase complex. Arch. Biochem. Biophys. 308:446-453.

30. Marshall, L., and A. DiGeorge. 1981. Maple syrup urine disease in the old order Mennonites. Am. J. Hum. Genet. Suppl. 33:139A.

31. Fraga, J. M., and J. R. Alonso-Fernandez. 1987. Neonatal screening programmes in Spain: 1982- 1986. In Advances in Neonatal Screening. B. L. Therrell, editor. Elsevier Science Publishers, Amsterdam. 487-488.

32. Naylor, E. W. 1980. Newborn screening for maple syrup urine disease (branched-chain ketoaciduria). In Neonatal Screening for Inborn Errors of Metabolism. H. Bickel, R. Guthrie, and G. Hamersen, editors. Springer-Verlag, Berlin $19-28$

33. Hartl, F. U., and J. Martin. 1992. Protein folding in the cell: The role of molecular chaperones Hsp70 and Hsp60. Annu. Rev. Biophys. Biomol. Struct. 21:293-322.

34. Martin, J., M. Mayhew, T. Langer, and F. U. Hartl. 1993. The reaction cycle of GroEL and GroES in chaperonin-assisted protein folding. Nature (Lond.). $366: 228-233$.

35. Wexler, I. D., S. G. Hemalatha, and M. S. Patel. 1991. Sequence conservation in the $\alpha$ and $\beta$ subunits of pyruvate dehydrogenase and its similarity to branched-chain $\alpha$-keto acid dehydrogenase. FEBS (Fed. Eor. Biochem. Soc.) Lett. 282:209-213.

36. Chou, P. Y., and G. D. Fasman. 1978. Prediction of the secondary structure of proteins from their amino acid sequence. Adv. Enzymol. 47:45-148. 